\title{
Kısıntılı Sulama Koşullarında Yetiştirilen Kıvırcık Marulda Bitki Kök Bölgesindeki Tuzluluk Birikimi
}

\author{
Salinity Accumulation in the Root Area of the Curly Lettuce Grown in Deficit Irrigation \\ Conditions
}

\author{
Harun KAMAN ${ }^{1^{*}}$, Halil DEMİR ${ }^{2}$, İlker SÖNMEZ ${ }^{3}$, Ersin POLAT ${ }^{4}$, \\ Salahudin Saed MOHAMOUD ${ }^{5}$, Zafer ÜÇOK ${ }^{6}$
}

\section{$\ddot{O} z$}

Bu çalışmada, kıvırcık marul bitkisi için sulama sezonu başlangıcına kıyasla sulama sezonu bitiminde meydana gelen kök bölgesi içindeki tuz birikimi durumu araştırılmıştır. 2018 yılı ilkbahar yetişme döneminde yay çatılı plastik örtülü bir serada yürütülen çalışmada, bitki materyali olarak Campania kıvırcık marul (Lactuca sativa var. crispa) çeșidi kullanılmıştır. Araştırmada, bitki kök bölgesinin her iki tarafının ıslatıldığı geleneksel sulama (GS125, GS100, GS75, GS50) ile birlikte ardışık yarı 1slatmalı sulama (AYIS125, AYIS100, AYIS75, AYIS50) uygulamaları ele alınmıștır. Ardışık yarı ıslatmalı sulama (AYIS) uygulamasında, sırasıyla takip eden sulamalarda ıslak ve kuru kısımlar yer değiștirilmiștir. Diğer bir ifadeyle, AYIS uygulamasında, sulamalar sırasında bitki kök bölgesinin bir yarısı görece olarak ıslatıılırken geriye kalan diğer yarısı görece olarak kuru bırakılmıs ve bir sonraki sulamada ıslak ve kuru bırakılan kısımlar yer değiştirilmiştir. Bitki kök bölgesi tuzluluk birikimini belirlemek için sulama sezonu başlangıcında üç yinelemeli olarak araziyi temsil edecek șekilde $0-10,10-20$ ve $20-30 \mathrm{~cm}$ derinliklerden toprak örneği alınmıştır. Benzer bir şekilde, sulama sezonu bitiminde de, yine üç yinelemeli olarak, her sulama uygulaması altında bitki kök bölgesinden toprak örnekleri alınmıştır. Geleneksel yöntem kullanılarak, laboratuvarda toprak örneklerinden çamur süzükleri elde edilmiş ve tuzluluk ölçümleri yapılmıştır. En düşük tuzluluk değeri GS100 uygulamasında $0.49 \mathrm{dS} \mathrm{m}^{-1}$ olarak ölçülürken, en yüksek tuzluluk değeri ise $1.400 .49 \mathrm{dS}$ $\mathrm{m}^{-1}$ olarak GS125 uygulamasında kaydedilmiştir. Genel olarak, sezon sonunda en yüksek tuzluluk artışı ilk katman $(0-10 \mathrm{~cm})$ için \%48, ikinci katman $(10-20 \mathrm{~cm})$ için \%34 ve üçüncü katman $(20-30 \mathrm{~cm})$ için $\% 45$ olarak GS125 sulama uygulamasında hesaplanmıştır. Bu artış oranları dikkate alınması gereken değerlerdir. Sonuç olarak, sürdürülebilir bir sulu tarım için yetişme sezonunda iyi bir drenaj sistemi vasıtasıyla, topraktaki tuz birikiminin etkin bir yıkama işlemiyle giderilmesi önerilmektedir.

Anahtar Kelimeler: Marul, Kısıntılı sulama, Yarı ıslatmalı sulama, Tuz yığıı̧ımı, Drenaj, Yıkama

\footnotetext{
1*Sorumlu Yazar/Corresponding Author: Harun Kaman, Akdeniz Üniversitesi, Ziraat Fakültesi, Tarımsal Yapılar ve Sulama Bölümü, 07058 Kampüs, Antalya, Türkiye. E-mail: hkaman@akdeniz.edu.tr (D) OrcID: 0000-0001-9308-3690

${ }^{2}$ Halil Demir, Akdeniz Üniversitesi, Ziraat Fakültesi, Bahçe Bitkileri Bölümü, 07058 Kampüs, Antalya, Türkiye. E-mail: hdemir@akdeniz.edu.tr (DD OrcID: 00000003-2237-5439

3 İlker Sönmez, Akdeniz Üniversitesi, Ziraat Fakültesi, Toprak Bilimi ve Bitki Besleme Bölümü, 07058 Kampüs, Antalya, Türkiye. E-mail: ilkersonmez@akdeniz.edu.tr (D) OrcID: 0000-0001-7264-7805

${ }^{4}$ Ersin Polat, Akdeniz Üniversitesi, Ziraat Fakültesi, Bahçe Bitkileri Bölümü, 07058 Kampüs, Antalya, Türkiye. E-mail: polat@akdeniz.edu.tr (D OrcID: 00000003-2414-5071

${ }^{5}$ Salahudin Saed Mohamoud, Akdeniz Üniversitesi, Ziraat Fakültesi, Bahçe Bitkileri Bölümü, 07058 Kampüs, Antalya, Türkiye. (DD OrcID: 0000-0002-6574-0355 ${ }^{6}$ Zafer Üçco, Akdeniz Üniversitesi, Ziraat Fakültesi, Bahçe Bitkileri Bölümü, 07058 Kampüs, Antalya, Türkiye. (D) OrcID: 0000-0001-8380-3551 Atıf/Citation: Kaman, H., Demir, H., Sönmez, İ., Polat, E., Mohamoud, S.S., Üçok, Z. Kısıntılı Sulama Koşullarında Yetiştirilen Kıvırcık Marulda Bitki Kök Bölgesindeki Tuzluluk Birikimi. Tekirdă̆ Ziraat Fakültesi Dergisi, 18 (3), 508-520.
}

CBu çalışma Tekirdağ Namık Kemal Üniversitesi tarafından Creative Commons Lisansı (https://creativecommons.org/licenses/by-nc/4.0/) kapsamında yayınlanmıştır. Tekirdağ 2021 


\begin{abstract}
Salt accumulation in the root zone at the end of the irrigation season compared to the beginning of the irrigation season was investigated for curly lettuce plants in this study. The study was conducted in a spring-roofed plasticcovered greenhouse in a spring growing season in 2018 and the Campania curly lettuce (Lactuca sativa var. crispa) variety was used as the plant material. The conventional drip irrigation (GS125, GS100, GS75 and GS50) and partial root drying technique (AYIS125, AYIS100, AYIS75 and AYIS50) applications were investigated in the study. In the alternate partial root drying technique (APRD) application, the wet and dry parts were replaced in the following irrigations, respectively. In other words, in APRD application, while one half of the plant root area was wetted relatively during irrigation, the remaining half was left relatively dry and the parts left wet and dry in the next irrigation were replaced. In order to determine the salinity accumulation in the plant root zone, soil samples were taken from 0-10, 10-20 and 20-30 cm depths to represent the soil in three replicates at the beginning of the irrigation season. Similarly, at the end of the irrigation season, soil samples were taken from the plant root area in three replicates under each irrigation application. Mud strainers were obtained from soil samples using the traditional method in the laboratory and salinity measurements were made. While the lowest salinity value was measured as $0.49 \mathrm{dS} \mathrm{m}^{-1}$ in GS100 application, the highest salinity value was recorded as $1.40 \mathrm{dS} \mathrm{m}^{-1}$ in GS125 application. In general, the highest salinity increase at the end of the season was calculated in GS125 irrigation application as $48 \%$ for the first layer $(0-10 \mathrm{~cm}), 34 \%$ for the second layer $(10-20 \mathrm{~cm})$ and $45 \%$ for the third layer $(20-30 \mathrm{~cm})$. These increase rates are values that should be taken into account. As a result, it is recommended to remove the salt accumulation in the soil by an effective washing process through a good drainage system end of the growing season for a sustainable irrigated agriculture.
\end{abstract}

Keywords: Lettuce, Deficit irrigation, Partial root drying Technique, Salt accumulation, Drainage, Leaching 


\section{Giriș}

Salata ve marulların anavatanı ve Dünya üzerinde yayılışı ile ilgili değişik görüşler bulunmaktadır. Anadolu, Kafkasya, İran ve Türkistan anavatanı olarak kabul edilmektedir. Marullar Türkiye'de açıkta ve örtüaltında yıl boyu yetiştirilebilen sebze türleri arasındadır (Şalk ve ark., 2008). Dünya marul üretimi 2018 yılında 27.3 milyon ton olarak gerçekleşmiş, lider ülke olarak Çin bu üretimin yaklaşık 15.5 milyon tonunu karşılamaktadır. Çin'de üretilen marulun büyük bir kısmı iç tüketimde kullanılmaktadır. Dünyanın en büyük marul ihracatçıları ise sırasıyla İspanya ve ABD'dir. Dünyanın değişik coğrafyalarında 1900'lü yılların başından beri geniş ölçekte üretilmeye başlanmıştır (Anonymous, 2017; Anonymous, 2018). Türkiye'de 2019 y1lında toplam 499766 ton marul üretimi gerçekleştirilmiş, bunun 198491 tonunu kıvırcık, 215725 tonunu göbekli ve 84160 tonunu ise baş salata (Iceberg) tipi marullar oluşturmuştur (Anonim, 2019). Marullar suyu çok seven bitki grubu olduğundan topraktaki su eksikliğine son derece hassastır. İklim değişikliği nedeniyle sıcaklıkların artması ve su kaynaklarının azalması nedeniyle suya olan ihtiyacın da önemli ölçüde artması beklenmektedir. Aynı zamanda nüfus artışı ve endüstriyel gelişme ile birlikte su stresi çok önemli hale gelecek, dolayısıyla bu durum, tarımdaki su kullanımının azaltılmasını zorunlu hale getirecektir (Kanber ve ark., 2010). Su stresi bir ürünün büyüme ve gelişmesini ciddi şekilde sınırlayan faktörlerden birisidir (Imanishi ve ark., 2007). Kuraklığın bitki gelişimine olumsuz etkilerini en aza indirgemek için sulama önemlidir. Ancak kuraklık, tuzluluk, besin dengesizliği ve ekstrem sıcaklıklar bitkisel verimi sınırlandıran ana çevresel faktörlerdir. Sulama, tarımsal üretimde kuraklık riski etkisinin azaltmasında önemli rol oynamaktadır. Bu nedenle, sulama yalnızca tarımsal üretim için değil aynı zamanda gıda güvenliğinin sağlanması açısından da önem taşımaktadır.

Bitkisel üretimde sulama uygulaması, üretimde artış sağlayan önemli bir girdidir (İstanbulluoğlu ve ark., 2006). Ancak, yanlış sulama uygulamaları tuzluluk vb sorunları ortaya çıkarmaktadır. Genel olarak, sulanan alanlarda yüksek ve tuzlu taban suyu problemi meydana gelebilmektedir (Konukcu ve Akbuğa, 2006). Suyun kit ve pahalı olduğu bölgelerde kısıntılı sulama ile mevsim içi sulamalarda optimum ürünü sağlamak koşuluyla gerekenden daha az su uygulayarak daha fazla tarım alanının sulanması amaçlanmaktadır. Kısıntılı sulama uygulaması genel olarak bitkilerin su eksikliğine dayanıklı (dirençli) dönemlerinde yapılmaktadır. Geleneksel kısıntılı sulama uygulaması altında su kullanımının azaltılması mümkün olabilmekte; ancak, meyve verimi ve kalitesinde önemli oranda düşmeler olmaktadır (Kirda ve Baytorun, 2000). Diğer bir kısıntılı sulama uygulaması da yarı ıslatmalı sulama (YIS) uygulamasıdır. YIS uygulaması ile geleneksel sulamalarda uygulanan su miktarı belirli bir oranda azaltılarak bitki köklerinin yarısı ıslatılmakta ve takip eden sulamalarda ise diğer yarısına su verilmektedir. Böylece suyun kıt ve pahalı olduğu bölgelerde geleneksel kısıntılı sulamaya benzer şekilde daha az su uygulayarak mevcut su kaynaklarından daha etkin şekilde yararlanılması amaçlanmaktadır (Kang ve ark., 1998). YIS uygulamasında bitki kök bölgesinin periyodik olarak yarısının ıslatılmasıyla, bilinen geleneksel kısıntılı sulama yöntemine göre su kullanım randımanının daha yüksek olabileceği ifade edilmektedir (Chaffey, 2001).

Bitkisel üretimde toprak tuzluluğu da verimi önemli oranda sınırlandırmaktadır. Bitki kök bölgesinde tuz yığgşımının artması sonucu, kök bölgesi içinde iyon dengesi bozulmakta ve bunun sonucu olarak bitkilerin beslenme durumu olumsuz etkilenmektedir (Öktüren Asri ve ark., 2013). Bitki kök bölgesindeki tuzluluk, sulu tarımın en önemli sorunlarının başında gelmekte ve daha çok, sulama uygulamalarına bağlı olarak ortaya çıkmaktadır. Sulama uygulamalarında yapılan yanlışlıklar, az veya fazla su kullanımı sulama suyunun randımanını azaltmakta ve üretimde düşmelere yol açmaktadır. Aşırı sulama, taban suyu artışı ve dolayısıyla toprak tuzluluğuna neden olmaktadır (Cetin ve Kirda, 2003). Tarımda, tuzluluk problemi olan alanların miktarı giderek artmaktadır. Topraktaki tuz birikiminin sayısal değerine göre bitki veriminde önemli oranda azalmalar meydana gelebilmektedir. Bu nedenle, sulama suyu miktarı ve uygulama biçimi hem bitkinin gereksinimini karşılamalı, hem de bitki kök bölgesinde tuz birikimine neden olmamalıdır. Bitkisel üretimde yetişme sezonu başlangıcındaki su ve toprak tuzluluğu bitki gelişimine olumsuz etkisi olmayacak kadar düşük düzeyde olsa dahi, zamanla toprakta tuz birikimi olabilmektedir. Çünkü, bitki kök bölgesine uygulanan sulama suyu azda olsa içerdiği erimiş/çözünmüş madde ve gübre uygulamaları sonucu toprakta tuz birikimine yol açmaktadır. Buna karşın, sulama suyu ve mevsim başlangıcı toprak tuzluluk değerlerinin düşük olduğu su-verim ilişkileri üzerine yürütülen araştırmalarda, genel olarak mevsim sonunda muhtemel tuz yığışımının araştırılıp irdelenmediği görülmektedir. Bu bağlamda ele alınan bu çalışmada, kıvırcık marul bitkisi için bir sulama sezonu başlangıcına göre sulama sezonu bitiminde meydana gelen kök bölgesi içindeki tuz birikimi durumu araştırılmıştır. 


\section{Materyal ve Metot}

Araştırma, 2018 Yı1ı İlkbahar Döneminde Akdeniz Üniversitesi Ziraat Fakültesi’nde yer alan $500 \mathrm{~m}^{2}$ alana sahip yay çatılı plastik bir serada yürütülmüştür. Araştırmanın yürütüldüğü alan $36^{\circ} 54^{\prime} 00.25$ kuzey enlemi ile $30^{\circ} 38^{\prime} 49.07$ doğu boylamında olup, denizden yüksekliği 37 metredir. Araştırma alanını temsilen 0-30 cm derinlikten toprak örneği alınmıştır. Toprak örneklerinde pH (Jackson, 1967), kireç (CaCO3) (Evliya, 1964), elektriksel iletkenlik (Anonymous, 1982), bünye (Bouyoucos, 1951), organik madde (Black, 1965), toplam N (Black, 1957), alınabilir P (Olsen ve Sommers, 1982), ekstrakte edilebilir K, Ca ve Mg (Kacar, 1972) ve alınabilir Fe, Zn, Cu ve Mn analizleri (Lindsay ve Norwell, 1978) yapılmıştır. Deneme alanı toprağının kimi fiziksel ve kimyasal özellikleri Tablo l'de verilmiştir. Araştırmanın yürütüldüğü Şubat, Mart ve Nisan aylarında deneme alanının minimum $\left({ }^{\circ} \mathrm{C}\right)$, ortalama $\left({ }^{\circ} \mathrm{C}\right)$, maksimum $\left({ }^{\circ} \mathrm{C}\right)$ sicaklık değerleri ile ortalama nem oranı (\%) Tablo 2'de görülebilir.

Tablo 1. Araştırma alanın kimi fiziksel ve kimyasal özellikleri

Table 1. Some physical and chemical characteristics of the study area

\begin{tabular}{lcc}
\hline Toprak özellikleri & Birim & Değer \\
\hline $\mathrm{pH}$ & - & 7.58 \\
Kireç & $\%$ & 16.62 \\
EC & $\mathrm{mS} / \mathrm{cm}$ & 0.45 \\
Bünye sınfı & $\% /$ & $\mathrm{T}$ ın \\
Organik madde & $\%$ & 1.57 \\
Toplam N & $\%$ & 0.077 \\
Alınabilir P & $\mathrm{mg} / \mathrm{kg}$ & 53.79 \\
Değişsebilir K & $\mathrm{mg} / \mathrm{kg}$ & 230.1 \\
Değişebilir Ca & $\mathrm{mg} / \mathrm{kg}$ & 3318.0 \\
Değişebilir $\mathrm{Mg}$ & $\mathrm{mg} / \mathrm{kg}$ & 268.8 \\
Alınabilir Fe & $\mathrm{mg} / \mathrm{kg}$ & 0.906 \\
Alınabilir $\mathrm{Mn}$ & $\mathrm{mg} / \mathrm{kg}$ & 1.192 \\
Alınabilir $\mathrm{Zn}$ & $\mathrm{mg} / \mathrm{kg}$ & 0.440 \\
Alınabilir $\mathrm{Cu}$ & $\mathrm{mg} / \mathrm{kg}$ & 0.292 \\
Alınabilir $\mathrm{Na}$ & $\mathrm{mg} / \mathrm{kg}$ & 52.9 \\
\hline
\end{tabular}

Tablo 2. Deneme alanının şubat, mart ve nisan aylarında minimum, ortalama, maksimum sıcaklık değerleri ile ortalama nem oranı

Table 2. Minimum, average, maximum temperature values and average humidity of the study area in February, March and April

\begin{tabular}{ccccc}
\hline Deneme ayları & $\begin{array}{c}\text { Minimum sıcaklık } \\
\left({ }^{\circ} \mathbf{C}\right)\end{array}$ & $\begin{array}{c}\text { Ortalama sıcaklık } \\
\left({ }^{\circ} \mathbf{C}\right)\end{array}$ & $\begin{array}{c}\text { Maksimum sıcaklık } \\
\left({ }^{\circ} \mathbf{C}\right)\end{array}$ & $\begin{array}{c}\text { Ortalama nem oranı } \\
(\%)\end{array}$ \\
\hline Şubat & 11.7 & 14.8 & 19.4 & 81.0 \\
Mart & 12.5 & 16.1 & 19.6 & 65.9 \\
Nisan & 16.1 & 19.6 & 24.0 & 59.5 \\
\hline
\end{tabular}

Araştırmada bitkisel materyal olarak Campania kıvırcık marul (Lactuca sativa var. crispa) çeşidi kullanılmıştır (Şekil 1). Çalışmada kullanılan Campania kıvırcık marul, büyük baş yapısı ve geniş adaptasyon yeteneği sayesinde 1lıman sahil bölgelerinde her dönem üretime uygun bir çeşittir. Çok geç sapa kalkma özelliğinin yanı sıra yaprak rengi orta-koyu yeşil, ortalama baş ağırlığ $800-1000 \mathrm{~g}$ arasında değişmektedir. Olgunluk süresi yetiştirme dönemi ve iklim koşullarına bağlı olarak değişmekte, sıcak dönemlerde 45-50 gün, soğuk dönemlerde ise 65-85 gündür. Marul mildiyösünün bazı ırklarına ve marul mozaik virüsüne dayanıklıdır (Anonim, 2018). Kıvırcık marul fideleri, 50×40 cm dikim mesafelerine göre seraya dikilmiştir. Araştırmada parsel büyüklüğü $2.4 \mathrm{~m}^{2}$ ve 3 yinelemeli olarak kurulmuş, sulama suyu ve gübre fertigasyon şeklinde damla sulama sistemiyle uygulanmıştır. Araştırmada, bitki kök bölgesinin her iki tarafının ıslatıldığı geleneksel sulama (GS125, GS100, GS75, GS50) ile birlikte ardışık yarı ıslatmalı sulama (AYIS125, AYIS100, AYIS75, AYIS50) uygulamaları ele alınmıştır. GS125, GS100, GS75 ve GS50 uygulamalarında A-Sınıfı Buharlaşma Kabı'ndaki değere göre sırasıyla \%125, \%100, \%75 ve \%50 oranlarında sulama suyu verilmiştir. AYIS125, AYIS100, AYIS75, AYIS50 uygulamalarında da yine A-Sınıfı Buhar Kabı'ndaki buharlaşmaya göre sırasıyla \%125, \%100, \%75 ve \%50 oranlarında sulama suyu hesaplanmıştır. Ancak, ardışık yarı ıslatmalı sulama (AYIS) uygulamalarında, bitki kök bölgesinin bir yarısı görece olarak sulanırken diğer yarısı görece olarak kuru 
bırakılmış ve takip eden sulamalarda ıslak ve kuru kısımlar görece olarak yer değiştirilmiştir. Diğer bir ifadeyle, AYIS uygulamalarında, sulamalar sırasında bitki kök bölgesinin bir yarısı görece olarak ıslatılırken geriye kalan diğer yarısı görece olarak kuru bırakılmış ve bir sonraki sulamada ılak ve kuru bırakılan kısımlar yer değiştirilmiştir. AYIS uygulamalarında çift damla sulama lateralleri kullanılmış ve ıslak- kuru kısımlar vanalar aracıllğıyla kontrol edilmiştir. Parsellere uygulanan sulama suyu miktarları A-Sınıfı Buharlaşma Kabı'ndan alınan buharlaşma ölçümleriyle aşağıdaki eşitlik (Eş. 1) kullanılarak hesaplanmıştır.

$\mathrm{I}=\mathrm{K} \times \mathrm{Ep} \times \mathrm{A}$

Eşitlikte: I, sulama suyu (litre); K: bitki örtü yüzdesi katsayısı (örtü yüzdesi değeri bitki gelişimine bağlı olarak 19 Mart 2018'e kadar 0.30, daha sonra 0.40 olarak alınmıştır.); Ep, A-Sınıfı Buharlaşma Kabı'ndan ölçülen buharlaşma (mm); A, sulanan alan $\left(\mathrm{m}^{2}\right)$.

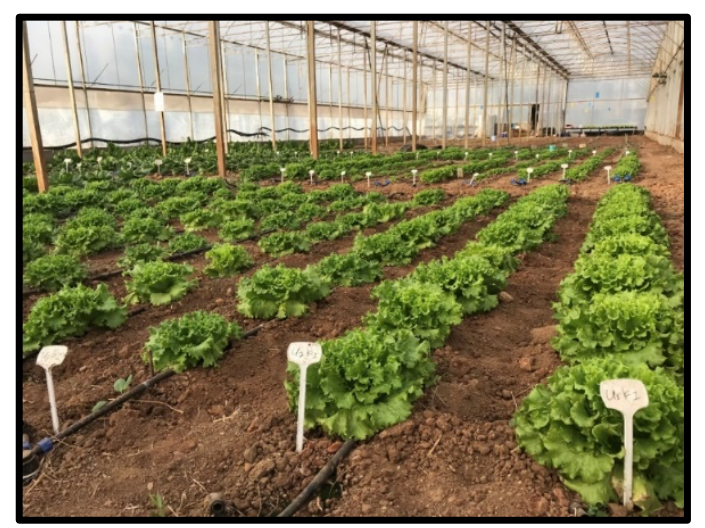

Figure 1. Campania curly lettuce variety used in the research

\section{Şekil 1. Araşstrmada kullanılan Campania kıvırcık marul çeşidi}

Araştırma 2018 yılı Şubat, Mart ve Nisan aylarında yürütülmüştür. Kıvırcek marul fideleri 5 Şubat 2018 tarihinde seraya dikilmiştir. Tüm uygulamalara 2 Mart 2018 tarihine kadar eşit bir şekilde sulamalar yapılmıştır. Anılan tarihten sonra konulu sulama uygulamalarına geçilmiştir. Sulama suyu miktarı kullanılabilir su tutma kapasitesini aşmayacak bir şekilde, yetişme dönemi ortasına dek haftada bir, daha sonra sıcaklıkların artması ve günlerin uzamasıyla birlikte haftada iki olacak şekilde sulama uygulamaları planlanmıştır.

Araştırmada kullanılan sulama suyu EC değeri $0.600 \mathrm{dS} \mathrm{m}^{-1}$ ve $\mathrm{pH}$ değeri ise $7.2^{\prime}$ dir. Sulama suyu saf su olmadığı için bitkisel üretimde sulama uygulamaları sonucu bitki kök bölgesinde zamanla tuz birikimi meydana gelebilmektedir. Ayıca, besin elementi olarak gübre uygulamaları da bitki kök bölgesindeki tuz birikimine katkı sağlamaktadır. Ele alınan bu araştırmada, ilave bir tuzluluk koşulu olmadan, mevcut sulama uygulamaları ve mevcut toprak özellikleri altındaki tuz birikimi araştııılmışır. Tuz birikimini belirlemek amacıyla, sezon başlangııında araziyi temsil edecek bir şekilde toprak örnekleri alınmıştır. Sezon sonunda da her bir sulama uygulamasındaki kıvırcık marul bitkisi kök bölgesinden toprak örneklemesi yapılmıştır. Toprak örnekleri $0-10 \mathrm{~cm}, 10-20 \mathrm{~cm}$ ve $20-30 \mathrm{~cm}$ derinliklerden olmak üzere üç yinelemeli olarak alınmıştır. Daha sonra, geleneksel yöntemle laboratuar koşullarında çamur süzüğü çıkarılarak, toprak örneklerinde tuzluluk (ECe, $\mathrm{dS} \mathrm{m}^{-1}$ ) ölçümleri gerçekleştirilmiştir.

\section{Araştırma Sonuçları ve Tartışma}

Araştırmada kıvırcık marul bitkisine, sulama uygulamaları (GS ve AYIS) ve sulama suyu düzeyleri ( $\% 125, \% 100, \% 75$ ve $\% 50)$ dışındaki tüm bakım, tarımsal işlemler vs. eşit bir şekilde yapılmıştır. Bu yüzden, sezon sonu itibarıly toprak tuzluluk değerlerindeki muhtemel değişimlere sadece sulama suyunun uygulama biçimi ve sulama suyu düzeyleri etki etmiştir. Sezon başı ve sezon sonunda olmak üzere toplam 81 adet toprak örneği üzerinde tuzluluk ölçümleri gerçekleştirilmiştir. Söz konusu toprak tuzluluk ölçümlerine ait değerlerin bazı tanımlayıc istatistiki bilgileri Tablo 3'de görülebilir. En düşük tuzluluk değeri GS100 uygulamasında 0.49 dS m${ }^{1}$ olarak ölçülmüştür. En yüksek tuzluluk değeri ise $1.40 \mathrm{dS} \mathrm{m}^{-1}$ olarak GS125 uygulamasında kaydedilmiştir. 
Sezon başı ve sezon sonunda sulama uygulamalarının tamamı (GS125, GS100, GS75, GS50, AYIS125, AYIS100, AYIS75 ve AYIS50) için kıvırcık marul bitkisinin kök bölgesi 0-30 cm derinliği için ortalama toprak tuzluluk değerlerinin (ECe, $\mathrm{dS} \mathrm{m}^{-1}$ ) değişimleri Şekil 2'de verilmiştir. Sezon başına kıyasla sezon sonunda, tuz birikimindeki en yüksek değer GS125 uygulamasında meydana gelmiştir (Şekil 2). Sezon sonu en düşük tuzluluk birikimi değeri ise GS50 uygulamasında belirlenmiştir (Şekil 2). GS125 ve AYIS125 sulama uygulamalarında toprak profilinin farklı katmanlarındaki $(0-10,10-20$ ve $20-30 \mathrm{~cm}$ derinlik) tuz birikimi değişimi Şekil 3'de görülebilir. Genel olarak toprak yüzeyine yakın bölgede tuzluluk birikiminin daha yüksek olduğu bulunmuştur. Sezon sonunda sezon başına kıyasla, GS125 sulama uygulamasındaki tuzluluk birikimi AYIS125 sulama uygulamasından daha fazla gerçekleşmiştir.

Tablo 3. Sezon başı ve sezon sonunda tüm sulama uygulamaları (GS125, GS100, GS75, GS50, AYIS125, AYIS100, AYIS75 ve AYIS50) altında, klvtrcı marul bitkisinin kök bölgesi (0-30 cm) tuzluluğunun kimi tanımlayıcı istatistiki değerleri

Table 3. Some descriptive statistical values of root zone salinity $(0-30 \mathrm{~cm})$ of curly lettuce plants under all irrigation treatments (GS125, GS100, GS75, GS50, AYIS125, AYIS100, AYIS75 and AYIS50) at the end of the season and the beginning of the season

\begin{tabular}{|c|c|c|c|c|c|c|c|c|c|}
\hline İstatistik & $\begin{array}{c}\text { Sezon } \\
\text { başı }\end{array}$ & GS125 & GS100 & GS75 & GS50 & AYIS125 & AYIS100 & AYIS75 & AYIS50 \\
\hline $\begin{array}{l}\text { Örnek } \\
\text { sayıs1 }\end{array}$ & 9 & 9 & 9 & 9 & 9 & 9 & 9 & 9 & 9 \\
\hline Ortalama & 0.707 & 1.010 & 0.746 & 0.676 & 0.647 & 0.780 & 0.784 & 0.731 & 0.817 \\
\hline En küçük & 0.500 & 0.570 & 0.490 & 0.610 & 0.550 & 0.640 & 0.560 & 0.600 & 0.620 \\
\hline En büyük & 0.860 & 1.400 & 1.080 & 0.870 & 0.730 & 0.990 & 1.190 & 1.160 & 1.150 \\
\hline $\begin{array}{c}\text { Standart } \\
\text { sapma }\end{array}$ & 0.129 & 0.315 & 0.164 & 0.094 & 0.061 & 0.109 & 0.192 & 0.168 & 0.170 \\
\hline
\end{tabular}

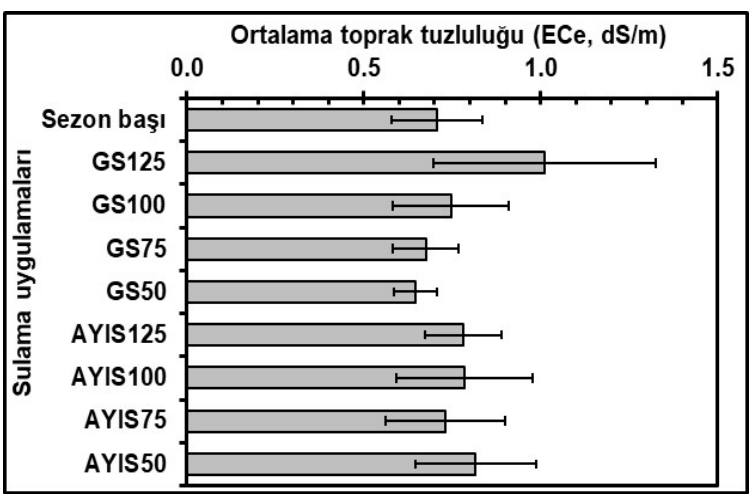

Figure 2. Average salinity change (ECe, $\left.d S \mathrm{~m}^{-1}\right)$ for 0-30 $\mathrm{cm}$ depth of curly lettuce plant under all irrigation treatments (GS125, GS100, GS75, GS50, AYIS125, AYIS100, AYIS75 and AYIS50) at the end of the season and the beginning of the season

Şekil 2. Sezon başı ve sezon sonunda tüm sulama uygulamaları (GS125, GS100, GS75, GS50, AYIS125, AYIS100, AYIS75 ve AYIS50) altında, kıvırcık marul bitkisinin kök bölgesi 0-30 cm derinliği için ortalama tuzluluk değişimi (ECe, $d S$ m $\left.^{-1}\right)$

GS100 ve AYIS100 sulama uygulamalarında toprak profilinin farkl katmanlarındaki $(0-10,10-20$ ve 20-30 cm derinlik) tuz birikimi değişimi Şekil 4'de verilmiştir. Genel olarak, buradaki toprak tuzluluğu birikimi GS125 ve AYIS125 sulama uygulamalarına (Şekil 3) kıyasla daha düşük gerçekleşmiştir. Öte yandan, aralarında fark düşük olmakla birlikte, GS100 sulama uygulamasındaki tuzluluk birikimi ilk iki katmanda (0-10 ve $10-20 \mathrm{~cm}$ derinlik için) AYIS100 sulama uygulamasından daha fazla gerçekleşmiştir (Şekil 4). GS75 ve AYIS75 sulama uygulamalarında toprak profilinin farklı katmanlarındaki $(0-10,10-20$ ve 20-30 cm derinlik) tuz birikimi değişimi Şekil 5'de sunulmuştur. Genel olarak, buradaki toprak tuzluluğu birikimi GS125 ve AYIS125 sulama uygulamaları (Şekil 3) ile GS100 ve AYIS100 sulama uygulamalarına (Şekil 4) kıyasla daha düşük gerçekleşmiştir. Öte yandan, GS75 sulama uygulaması ikinci katmanda $(10-20 \mathrm{~cm}$ derinlik) tuzluluk birikimi, AYIS75 sulama uygulamasından daha fazla olarak saptanmıştır (Şekil 5). GS50 ve AYIS50 sulama uygulamalarında toprak profilinin farklı katmanlarındaki (0-10, 10-20 ve 20-30 cm derinlik) tuz birikimi değişimi Şekil 6'de görülebilir. AYIS50 sulama 
uygulamasındaki tuzluluk birikimi, genel olarak GS50 sulama uygulamasından daha fazla olarak kaydedilmiştir (Şekil 6).

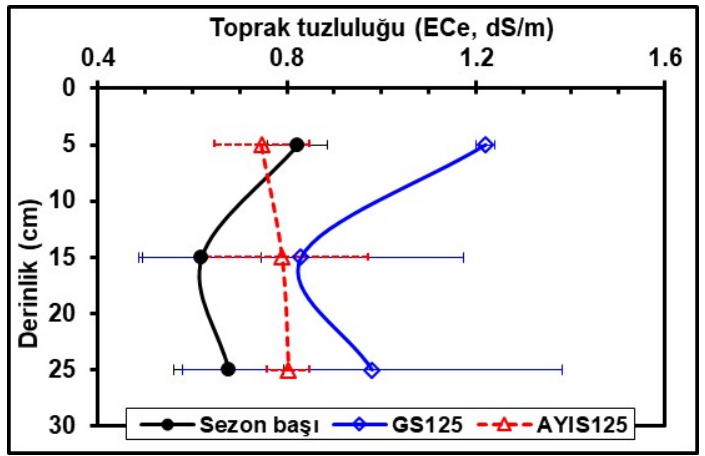

Figure 3. Salinity change (ECe, $\left.d S \mathrm{~m}^{-1}\right)$ within the root zone of curly lettuce plant under GS125 and AYIS125 treatments at the beginning and end of the season

Şekil 3. Sezon başı ile sezon sonunda GS125 ve AYIS125 uygulamaları altında kıvırcık marul bitkisinin kök bölgesi içinde tuzluluk değişimi (ECe, dS m m $^{-1}$

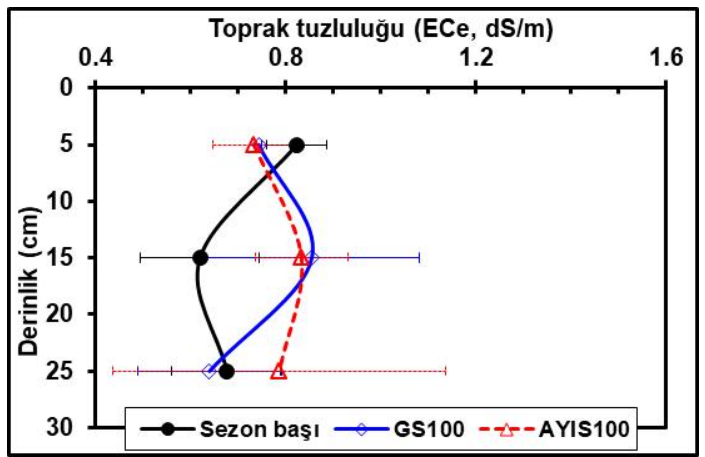

Figure 4. Salinity change (ECe, $d S \mathrm{~m}^{-1}$ ) within the root zone of curly lettuce plant at the beginning and end of the season under GS100 and AYIS100 treatments

Şekil 4. Sezon başı ile sezon sonunda GS100 ve AYIS100 uygulamaları altında kıvırcık marul bitkisinin kök bölgesi içinde tuzluluk değişimi (ECe, dS m $\left.{ }^{-1}\right)$

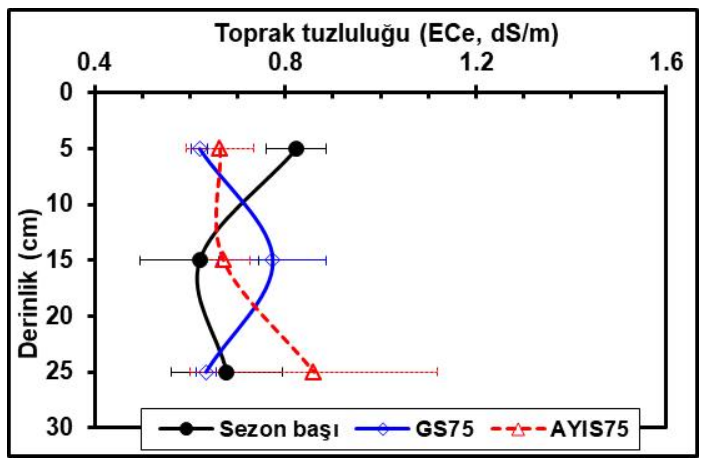

Figure 5. Salinity change (ECe, $\left.d S \mathrm{~m}^{-1}\right)$ in the root zone of curly lettuce plant at the beginning and end of the season under GS75 and AYIS75 treatments

Şekil 5. Sezon başı ile sezon sonunda GS75 ve AYIS75 uygulamaları altında kıvırcık marul bitkisinin kök bölgesi içinde tuzluluk değişimi (ECe, dS m $\left.{ }^{-1}\right)$ 


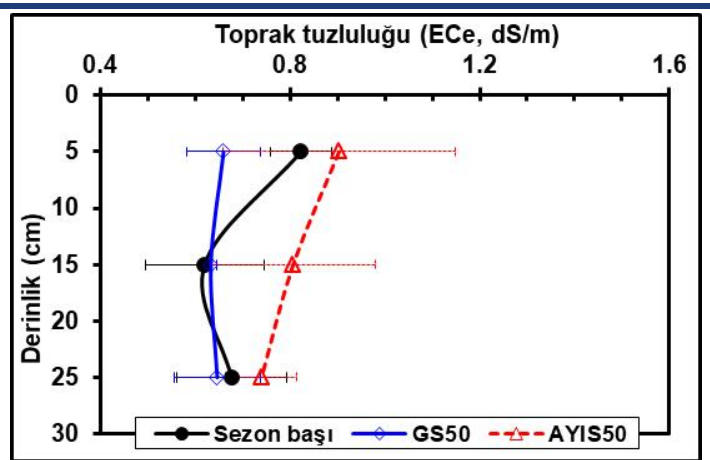

Figure 6. Salinity change (ECe, $\left.d S \mathrm{~m}^{-1}\right)$ within the root zone of curly lettuce plant at the beginning and end of the season under GS50 and AYIS50 treatments

Şekil 6. Sezon başı ile sezon sonunda GS50 ve AYIS50 uygulamalar altında kıvırcık marul bitkisinin kök bölgesi içinde tuzluluk değişimi (ECe, $d S$ m $\left.^{-1}\right)$

Sulama sezonu sonu itibarıyla, topraktaki tuzluluk birikiminin belirlenmesinde, ölçülen değerlerin (ECe, $\left.\mathrm{dS} \mathrm{m}^{-1}\right)$ yanısıra artış/azalış oranlarının (\%) ifadesi de çok önemlidir. Çünkü, topraktaki tuzluluk birikiminin ölçülen değerleri (ECe, $\mathrm{dS} \mathrm{m}^{-1}$ ) sezon başı tuzluluğunun düşük ve/veya sulama suyunun iyi kaliteye sahip olması neticesinde, sulama sezonu sonunda rakamsal olarak çok yüksek tuzluluk değerleri ölçülemeyebilir. Ancak, artış/azalış oranları (\%), tuzlu toprak ve/veya düşük kaliteye sahip suların kullanılması durumları için bir takım öngörü oluşturacaktır. Bu nedenle, ele alınan bu çalışmada Şekil 7'den Şekil 10'a kadarki grafiklerde, kıvırcık marul bitkisinin bitki kök bölgesi içinde ve farklı katmanlarında (0-10, 10-20 ve 20-30 cm derinlik) sezon sonundaki tuzluluk artış/azalış değişimleri verilmiştir.

Sezon başına kıyasla, kıvırcık marul bitkisinin GS125 ve AYIS125 sulama uygulamaları altında bitki kök bölgesi içinde ve farklı katmanlarında (0-10, 10-20 ve 20-30 cm derinlik) sezon sonundaki tuzluluk artış/azalış değişimi (\%) Şekil 7'de görülebilir. Sezon başına kıyasla sezon sonunda ilk katman (0-10 cm) için GS125 sulama uygulamasında yaklaşık \%48 oranında bir tuzluluk artışı hesaplanırken, AYIS125 sulama uygulamasında ise yaklaşık \% 0 oranında bir azalış belirlenmiştir. İkinci katmanda (10-20 cm) GS125 sulama uygulamasında yaklaşık \%34 oranında bir tuzluluk artışı saptanırken, AYIS125 sulama uygulamasında ise yaklaşık \%27'lik bir artış kaydedilmiştir. Üçüncü katmanda (20-30 cm) ise GS125 sulama uygulamasında yaklaşık \%45 oranında bir artış hesaplanırken, AYIS125 sulama uygulamasında ise yaklaşık \%19'luk bir artış belirlenmiştir.

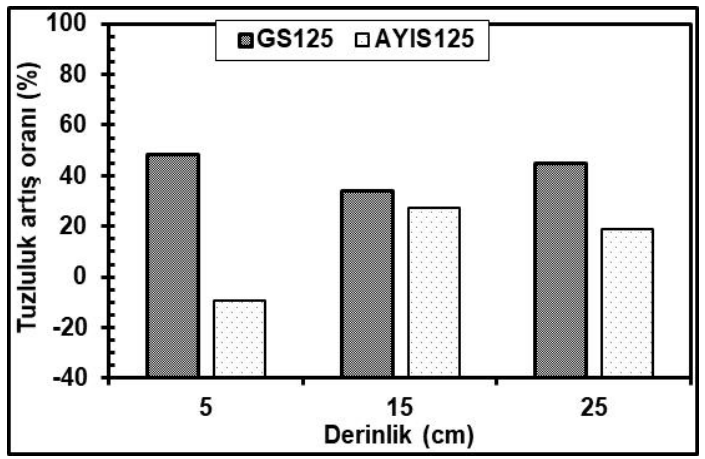

Figure 7. The change in salinity increase/decrease (\%) in the root zone of curly lettuce plant under GS125 and AYIS125 treatments at the end of the season compared to the beginning of the season

\section{Şekil 7. Sezon başı değerlerine kıyasla sezon sonunda GS125 ve AYIS125 uygulamaları altında, kıvırcık marul bitkisinin kök bölgesi içindeki tuzluluk artış/azalış değişimi (\%)}

Sezon başına kıyasla, kıvırcık marul bitkisinin GS100 ve AYIS100 sulama uygulamaları altında bitki kök bölgesi içinde ve farklı katmanlarında (0-10, 10-20 ve 20-30 cm derinlik) sezon sonundaki tuzluluk artış/azalış değişimi (\%) Şekil 8'de verilmiştir. Sezon başına kıyasla sezon sonunda ilk katman (0-10 cm) için GS100 sulama uygulamasında yaklaşı \% 10 oranında bir tuzluluk azalışı hesaplanırken, AYIS100 sulama uygulamasında ise yaklaşık \%11 oranında 
bir azalış belirlenmiştir. İkinci katmanda $(10-20 \mathrm{~cm})$ GS100 sulama uygulamasında yaklaşık \%38 oranında bir tuzluluk artışı saptanırken, AYIS100 sulama uygulamasında ise yaklaşı \%34'lük bir artış kaydedilmiştir. Üçüncü katmanda $(20-30 \mathrm{~cm})$ ise GS100 sulama uygulamasında yaklaşık \%5 oranında bir azalış hesaplanıken, AYIS100 sulama uygulamasında ise yaklaşık \%16'lık bir artış belirlenmiştir. Sezon başına kıyasla, kıvırcık marul bitkisinin GS75 ve AYIS75 sulama uygulamaları altında bitki kök bölgesi içinde ve farklı katmanlarında (0-10, 10-20 ve 20-30 cm derinlik) sezon sonundaki tuzluluk artış/azalış değişimi (\%) Şekil 9'da sunulmuştur. Sezon başına kıyasla sezon sonunda ilk katman $(0-10 \mathrm{~cm})$ için GS75 sulama uygulamasında yaklaşık \%25 oranında bir tuzluluk azalışı hesaplanırken, AYIS75 sulama uygulamasında ise yaklaşı \%19 oranında bir azalış belirlenmiştir. İkinci katmanda $(10-20 \mathrm{~cm})$ GS75 sulama uygulamasında yaklaşık \%25 oranında bir tuzluluk artışı saptanırken, AYIS75 sulama uygulamasında ise yaklaşık \% $\%$ 'lik bir artış kaydedilmiștir. Üçüncü katmanda $(20-30 \mathrm{~cm})$ ise GS75 sulama uygulamasında yaklaşık \%6 oranında bir azalış hesaplanırken, AYIS75 sulama uygulamasında ise yaklaşık \%27'lik bir artı̧s saptanmıştır.

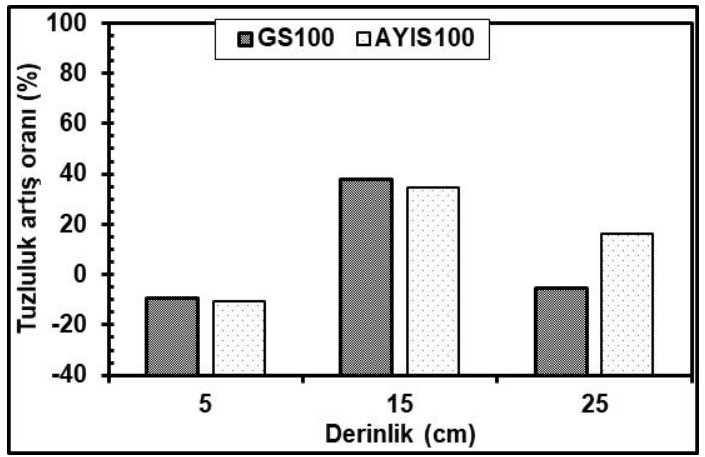

Figure 8. The change in salinity increase/decrease (\%) in the root zone of curly lettuce plant under GS100 and AYIS100 treatments at the end of the season compared to the beginning of the season

Şekil 8. Sezon başı değerlerine kıyasla sezon sonunda GS100 ve AYIS100 uygulamaları altında, kıvırcık marul bitkisinin kök bölgesi içindeki tuzluluk artı̧̧/azalı̧̧ değ̌isimi (\%)

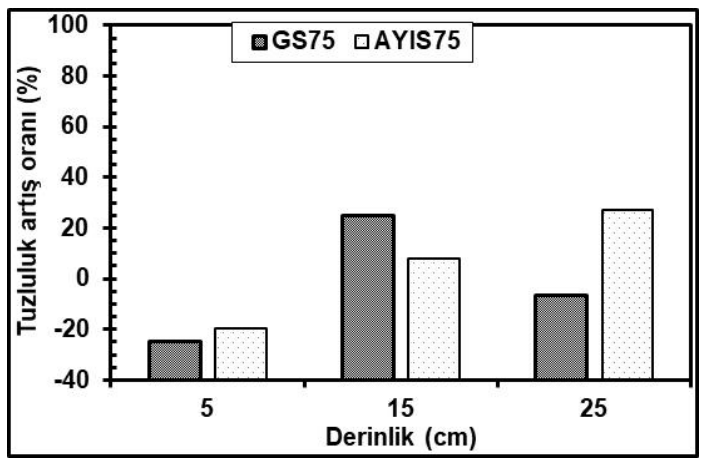

Figure 9. The change in salinity increase/decrease (\%) in the root zone of curly lettuce plant under GS75 and AYIS75 treatments at the end of the season compared to the beginning of the season

\section{Şekil 9. Sezon başı değerlerine kuyasla sezon sonunda GS75 ve AYIS75 uygulamaları altında, kivircık marul bitkisinin kök bölgesi içindeki tuzluluk artı̧̧/azalış değişimi (\%)}

Sezon başına kıyasla, kıvırcık marul bitkisinin GS50 ve AYIS50 sulama uygulamaları altında bitki kök bölgesi içinde ve farklı katmanlarında (0-10, 10-20 ve 20-30 cm derinlik) sezon sonundaki tuzluluk artış/azalış değişimi (\%) Şekil 10'da sunulmuştur. Sezon başına kıyasla sezon sonunda ilk katman $(0-10 \mathrm{~cm})$ için GS50 sulama uygulamasında yaklaşık \%20 oranında bir tuzluluk azalışı hesaplanırken, AYIS50 sulama uygulamasında ise yaklaşık \%10 oranında bir artş̧ belirlenmiştir. İkinci katmanda $(10-20 \mathrm{~cm})$ GS50 sulama uygulamasında yaklaşı $\% 2$ oranında bir tuzluluk artışı saptanırken, AYIS50 sulama uygulamasında ise yaklaşı \%30'luk bir artış kaydedilmiştir. Üçüncü katmanda $(20-30 \mathrm{~cm})$ ise GS50 sulama uygulamasında yaklaşı \%4 oranında bir azalıs hesaplanırken, AYIS50 sulama uygulamasında ise yaklaşı \%9'luk bir artış belirlenmiş̧ir. 


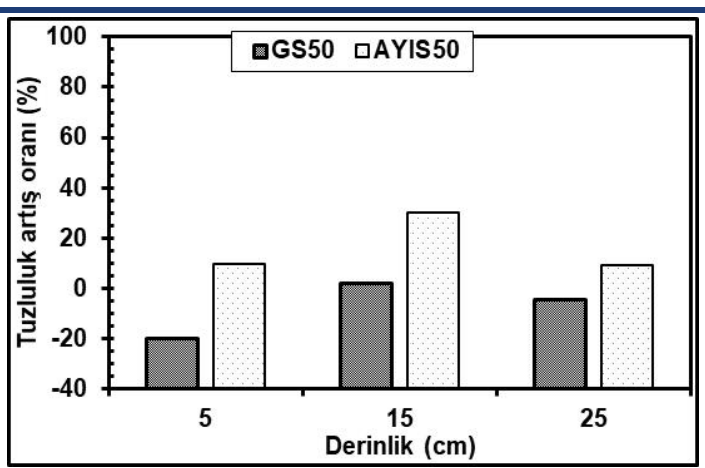

Figure 10. The change in salinity increase/decrease (\%) in the root zone of curly lettuce plant under GS50 and AYIS50 treatments at the end of the season compared to the beginning of the season

\section{Şekil 10. Sezon başı değerlerine kıyasla sezon sonunda GS50 ve AYIS50 uygulamaları altında, kıvırcık marul bitkisinin kök bölgesi içindeki tuzluluk artış/azalış değişimi (\%)}

Yarı 1slatmalı sulama, geleneksel sulama ve kısıntılı sulama uygulamaları ile ilgili literatürde çok sayıda araştırmaya rastlamak mümkündür. Araştırmalarda genel olarak su-verim ilişkileri üzerinde çalışmıştır (Kirda ve ark., 2004; Kirda ve ark., 2005; Kirda ve ark., 2007; Kaman ve ark., 2011). Öte yandan, kullanılan toprak ve sulama suyu tuzluluk yönünden sorunsuz olsa da zamanla toprakta tuzluluk birikimi olmaktadır. Çünkü her ne kadar sulama suyu iyi kaliteye sahip olursa olsun, azda olsa içerisinde eriyik/çözünmüş maddeler bulundurnaktadır. İlave olarak gübre uygulamaları sirasında da toprakta tuz birikimi meydana gelmektedir. Kısıtlı sulama stratejilerinin su tasarrufu sağladığı ancak düşük kaliteli sularla sulamanın toprağın tuzlanmasını artırabileceği ifade edilmektedir (Aragüés ve ark., 2014; Alomran ve ark., 2013). Bu konuda yapılan çeşitli araştırmalar, toprak tuzlanmasının yetersiz sulamaya bağlı potansiyel bir sorun olduğunu belirtmiştir (Kaman ve ark., 2006; Hsiao ve ark., 2007; Raine ve ark., 2007).

İyi kaliteye sahip su ve toprak koşullarında da bitki kök bölgesindeki tuz yığışımının araştırıldığı çalışmalar da yürütülmüştür (Kaman ve ark., 2006; Kaman ve Özbek, 2012; Kaman ve Özbek, 2016a; Kaman ve Özbek, 2016b; Kaman ve ark., 2020). Sözkonusu araştırmalarda da buradaki bulgulara benzer sonuçlar elde edilmiştir. Kanber ve Ünlü (2010)'un aktardığına göre, Maas (1986) marul bitkisini tuza orta derecede dayanıklı (4 dS m $\mathrm{m}^{-1}$ ile $10 \mathrm{dS} \mathrm{m}^{-1}$ arasında) bir sebze olarak bildirilmiştir. Tarafımızdan yapılan çalışmada ise en yüksek tuzluluk değeri ise $1.40 \mathrm{dS} \mathrm{m}^{-1}$ olarak saptanmıştır. Söz konusu tuzluluk değeri, Maas (1986) tarafından bildirilen değerlerin çok altındadır. Öte yandan, yine Kanber ve Ünlü (2010)'un aktardığına göre, Ayers ve Westcot (1989) tarafindan \%0 verim kaybı için toprak tuzluluk eşik değeri $1.30 \mathrm{dS} \mathrm{m}^{-1}$ ve sulama suyu tuzluluk eşik değeri ise $0.90 \mathrm{dS} \mathrm{m}^{-1}$ olarak açıklanmıştır. Tarafimızdan yapılan çalışmada sezon sonu itibarıyla ölçülen en yüksek tuzluluk değeri $\left(1.40 \mathrm{dS} \mathrm{m}^{-1}\right) \% 0$ verim kaybı için Ayers ve Westcot (1989) tarafından bildiren değeri $\left(1.30 \mathrm{dS} \mathrm{m}^{-1}\right)$ küçük bir fark $\left(0.10 \mathrm{dS} \mathrm{m}^{-1}\right)$ ile olsa da aşmıştır. İlave olarak, sezon başına kıyasla sezon sonu tuzluluk değerlerindeki artış oranları (\%) çok daha önemlidir. Çünkü artış miktarındaki oransal (\%) ifadeler, tuzluluğu yüksek toprak ve/veya sulama suyu koşulları için öngörüde bulunmayı sağlayacaktır. Araştırmada, sezon başlangıcına kıyasla sezon sonunda tuzluluk değerlerinde \%48 düzeyinde bir artışı meydana gelebildiği için tuzlu toprak ve sulama suyu koşulları için sulama yönetimi son derece daha dikkatli yapılmalıdır.

\section{Sonuç}

Araştırmada, kıvırcık marul bitkisine sulama uygulamaları (GS ve AYIS) ve sulama suyu düzeyleri (\%125, \%100, \%75 ve \%50) dışındaki tüm tarımsal işlemler eşit bir şekilde yapılmıştır. Genel olarak kullanılabilir su tutma kapasitesinin üzerinde bir su miktarı uygulanırsa, uygun drenaj koşullarında yıkama olabilir. Bu durumda da, fazla su uygulanan parsellerde yıkamadan dolayı daha düşük bir tuz birikimi beklenir. Ancak, bu çalışmada, fazla su diğer uygulamalara (\%75 ve \%50) kıyasla fazla anlamındadır. Diğer bir ifadeyle, kullanılabilir su tutma kapasitesini aşan bir sulama sözkonusu değildir. Bu durumda, yıkama düzeyinde olmayan fazla su, daha çok tuz birikimi anlamına gelir. Dolayısıyla, sezon sonu itibarıyla toprak tuzluluk değerlerindeki değişimlere, sadece sulama suyunun uygulama biçimi ve sulama suyu düzeyleri etki etmiştir.

Çalışmada toplam 81 adet toprak örneği üzerinde tuzluluk ölçümleri yapılmıştır. En düşük tuzluluk değeri $0.49 \mathrm{dS}$ $\mathrm{m}^{-1}$ olarak ölçülürken, en yüksek tuzluluk değeri ise $1.40 \mathrm{dS} \mathrm{m}{ }^{-1}$ olarak GS125 uygulamasında kaydedilmiştir. Genel olarak, sezon sonunda en yüksek tuzluluk artışı ilk katman $(0-10 \mathrm{~cm})$ için \%48, ikinci katman $(10-20 \mathrm{~cm})$ için \%34 ve 
üçüncü katman (20-30 cm) için \%45 olarak GS125 sulama uygulamasında hesaplanmıştır. Bu artı̧ oranları dikkate alınması gereken değerlerdir. Elde edilen değerlerin marul yetiştiriciliğinde risk oluşturacak düzeylere gelmemesi kısıntılı ve geleneksel sulama uygulamalarının etkinliği bakımından önemli görülmektedir. Sonuç olarak, sürdürülebilir bir sulu tarım için yetişme sezonunda iyi bir drenaj sistemi vasitasıyla, topraktaki tuz birikiminin etkin bir yıkama işlemiyle giderilmesi önerilmektedir.

\section{Teșekkür}

$\mathrm{Bu}$ çalışma, Akdeniz Üniversitesi Bilimsel Araştırma Projeleri Koordinasyon Birimi tarafindan FBA-2018-3129 numarası ile desteklenen projeden üretilmiştir. Anılan projede göbekli ve kıvırcık marul olmak üzere iki farklı marul çeşidi kullanılmış olup, göbekli marul ile ilgili çalışma Kaman ve ark. (2020) tarafindan yayımlanmıştır. 


\section{Kaynakça}

Alomran, A. M., Louki, I. I., Aly, A. A., Nadeem, M. E. (2013). Impact of deficit irrigation on soil salinity and cucumber yield under greenhouse condition in an arid environment. Journal of Agricultural Science and Technology 15: 1247-1259.

Anonim (2018). https://www.fidanfide.com/campania-kivircik-marul-fidesi. [Son erişim tarihi: 13.06.2018].

Anonim (2019). Bitkisel Üretim İstatistikleri, https://data.tuik.gov.tr/tr/display-bulletin/?bulletin=bitkisel-uretim-istatistikleri-2019-30685\#, Son Erişim Tarihi: 19.10.2020

Anonymous (1982). Methods of Soil Analysis (Ed. A.L. Page). Number 9, Part 2, Madison, Wisconsin, USA, 1159 pp.

Anonymous (2017). http://www.worldatlas.com/articles/world-leaders-in-lettuce production.html. [Son erişim tarihi: 23.07.2017].

Anonymous (2018). Food and Agriculture Organization of the United Nations. http://www.fao.org/faostat/en/\#data, Son Erişim tarihi: 19.10.2020.

Aragüésa, R., Medinaa, E. T. Martínez-Cobb, A., Faci, J. (2014). Effects of deficit irrigation strategies on soil salinizationand sodification in a semiarid drip-irrigated peach orchard. Agricultural Water Management 142: 1-9.

Ayers, R.S., Westcot, D.W. (1989). Water quality for agriculture. Irrigation and Drainage Paper, Food and Agriculture Organization of the United Nations, 29, Rev.1. Rome, 173 s.

Black, C. A. (1957). Soil-plant relationships. John Wiley and Sons, Inc., New York.

Black, C. A. (1965). Methods of Soil Analysis Part 2, Amer. Society of Agronomy Inc., Publisher Madisson, Wilconsin, U.S.A., p:1372-1376.

Bouyoucos, G. J. (1951). A recalibration of the hydrometer method for making mechanical analysis of the soils. Agronomy Journal 4(9): 434.

Cetin, M., Kirda, C. (2003). Spatial and temporal changes of soil salinity in a cotton field irrigated with low-quality water. Journal of Hydrology 272: $238-249$.

Chaffey, N. (2001). Restricting water supply enhances crop growth. Trends in Plant Science 6: pp. 346.

Evliya, H. (1964). Kültür Bitkilerinin Beslenmesi. Ankara Üniversitesi Ziraat Fakültesi Yayınları, Sayı:10, Ankara.

Hsiao, T., Steduto, P., Fereres, E. (2007). A systematic and quantitative approach toimprove water use efficiency in agriculture. Irrig. Sci. 25: 209-231.

Imanishi, J., Morimoto, Y., Imanishi, A., Sugimoto, K., Isoda, K. (2007). The independent detection of drought stress and leaf density using hyperspectral resolution data. Landscape Ecol Eng 3:55-65.

İstanbulluoğlu, A., Konukcu, F., Kocaman, İ. (2006). Development of Water Resources and Agricultural Practices under Irrigation in Thrace Region: Analysis of Existing Data for the Solution of Problems. Tekirdağ Ziraat Fakültesi Dergisi- Journal of Tekirdag Agricultural Faculty 3(2): 139-152.

Jackson, M. L. (1967). Soil Chemical Analysis. Prentice Hall of India Private Limited, New Delhi.

Kacar, B. (1972). Bitki ve Toprağın Kimyasal Analizleri. II. Bitki Analizleri, A.Ü. Ziraat Fak. Yayınları: 453, Ankara.

Kaman, H., Kirda, C., Cetin, M., Topcu, S. (2006). Salt accumulation in the root zones of tomato and cotton irrigated with partial root-drying technique. Irrigation and Drainage 533-544.

Kaman, H., Kirda, C., Sesveren, S. (2011). Genotypic differences of maize in grain yield response to deficit irrigation. Agricultural Water Management 98(5): 801-807.

Kaman, H., Özbek, Ö. (2012). Salt and water distributions in the plant root zone under deficit irrigation. Journal of Food, Agriculture \& Environment 496-500.

Kaman, H., Özbek, Ö. (2016a). Salt accumulation in the root zone of eggplant irrigated using partial root drying technique. International Journal of Agriculture \& Biology 18: 435-440.

Kaman, H., Özbek, Ö. (2016b). Salinity Accumulation in the Root Zones of Cucumber under Drip Irrigation Practices. Proceedings of the VI Balkan Symposium on Vegetables and Potatoes, Acta Hortic. 1142: 75-80.

Kaman, H., Demir, H., Sonmez, I., Polat, E., Mohamoud, S.S., Ucok, Z. (2020). Salinity of the root zone of lettuce irrigated with partial root drying. Fresenius Environmental Bulletin 29(09A): 8496-8502.

Kanber, R., Bastuğ, R., Büyüktaş, D., Ünlü, M., Kapur, B. (2010). Küresel İklim Değişikliğinin Su Kaynakları Ve Tarımsal Sulamaya Etkileri, sayfa 83-118, Türkiye.

Kanber, R., Ünlü, M. (2010). Tarımda Su ve Toprak Tuzluluğu. Ç.Ü. Ziraat Fakültesi, Genel Yayın No: 281, Kitap Yayın No: A-87, Adana.

Kang, S., Liang, Z., Hu, W., Zhang, J. (1998). Water use efficiency of controlled alternate irrigation on root- divided maize plants. Agricultural Water Management 38: 69-76.

Kirda, C., Baytorun, N. (2000). Fertigation under Saline Conditions: Irrigation Management Minimizing Soil Salinity Risk. In the Plant Nutrient Management under Pressurized Irrigation Systems in the Mediterranean Region by Ryan, J. (ed), Proceedings of the IMPHOS 
Kaman \& Demir \& Sönmez \& Polat \& Mohamoud \& Üçok Kısıntılı Sulama Koşullarında Yetiştirilen Kıvırcık Marulda Bitki Kök Bölgesindeki Tuzluluk Birikimi International Fertigation Workshop Organized by the World Phosphate Institute (IMPHOS), 25-27 April 1999, Amman, Jordan. ICARDA, Aleppo, Syria, pp. 288-296.

Kirda, C., Cetin, M., Dasgan, Y., Topcu, S., Kaman, H., Ekici, B., Derici, M. R., Ozguven, A. I. (2004). Yield response of greenhouse grown tomato to partial root drying and conventional deficit irrigation. Agricultural Water Management 69: 191-201.

Kirda, C., Topcu, S., Kaman, H., Ulger, A. C., Yazici, A., Cetin, M., Derici, M. R. (2005). Grain yield response and n-fertiliser recovery of maize under deficit irrigation. Field Crop Res. 93: 132-141.

Kırda, C., Topaloğlu, F., Topçu, S., Kaman, H. (2007). Mandarin yield response to partial root drying and conventional deficit irrigation. Turk. J. Agric. For., 31: 1-10.

Konukcu, F., Akbuğa, R. (2006). Impact of Shallow and Saline Water Tables on the Soil's Water and Salt Balance of Konya-Cumra District under Irrigation. Tekirdağ Ziraat Fakültesi Dergisi- Journal of Tekirdag Agricultural Faculty 3(2): 105-117.

Lindsay, W. L., Norvell, W. A. (1978). Development of a DTPA soil test for Zinc, Iron, Manganese and Copper. Soil Science Society of America Journal 42(3): 421-428.

Maas, E. W. (1986). Salt tolerance of plants. Applied Agriculture Research 1:12-26.

Olsen, S. R., Sommers, E. L. (1982) Phosphorus Availability Indices. Phosphorus soluble in sodium bicarbonate. In: Methods of soil analysis, Part II. Chemical and microbiological properties. ASA-SSSA, Agronomy Series, No:9. Madison. Wisconsin, USA. pp.404-430.

Öktüren Asri, F., Demirtaş, E.I., Arı, N., Özkan, F. (2013). Determination of irrigation water qualities of Bilecik-Osmaneli district. Akdeniz Univ. Ziraat Fak. Derg. 26(1): 49-55.

Raine, S. R., Meyer, W. S., Rassam, D. W., Hutson, J. L., Cook, F. J. (2007). Soil-water andsolute movement under precision irrigation: knowledge gaps for managing sus-tainable root zones. Irrig. Sci. 26: 91-100.

Şalk, A., Arın, L., Deveci, M., Polat, S. (2008). Özel Sebzecilik. Namık Kemal Üniversitesi, Ziraat Fakültesi, Onur Grafik, Matbaa ve Reklam, İstanbul. 